\title{
Malignant Skin Tumours in Jos University Teaching Hospital, Jos, Nigeria (Hospital Based Study)
}

\author{
*B. M. Mandong, K. S. Orkar, A. Z. Sule and N. L. Dakum
}

Departments of *Pathology and Surgery, Jos University Teaching Hospital, Jos, Nigeria.

Reprint requests to: Dr B. M. Mandong, Department of Pathology, Jos University Teaching Hospital, P. M. B. 2076, Jos, Nigeria.

\section{ABSTRACT}

Background: The incidence of melanoma has been on the increase in Australia and Asia but in Africa, many skin cancers arise from chronic ulcers and burns.

Methods: A retrospective histopathologic study of malignant skin tumours seen at the University of Jos Teaching Hospital, Jos, Nigeria in 5 years.

Results: A total of 128 malignant skin tumours were recorded during the period. Squamous cell carcinoma accounted for $51.2 \%$, malignant melanoma, $24.2 \%$ and Kaposi's sarcoma $10.9 \%$. Other tumours included fibrosarcoma, malignant fibrous histiocytoma and skin adnexal tumours. Skin cancer occurred in a younger age group compared to developed countries. The tumours presented either as nodular growth or non-healing, long-standing ulcers with an average duration of $5 \ldots 10$ years. This is in contrast to Europe where the duration of ulcer is $30-40$ years.

Conclusion: Skin cancers are not uncommon in our environment. Early treatment of ulcers, including grafing may improve the quality of life in these patients.

KEY WORDS: Skin cancer, squamous cell carcinoma, malignant melanoma, Kaposi's sarcoma, Jos

\section{Introduction}

Skin, the largest organ in the body is frequently afflicted by different types of diseases, including cancers. Malignant diseases of the skin arise not only primarily from the epithelial component but also from adnexal structures and dermal connective tissue. Cancer of the skin is found world wide though the frequency and pattern vary from region to region. 1-5 $^{-5}$ While basal cell carcinoma is the predormant skin cancer in the Caucasian prpulation of Europe and America, squamous cell carcinoma is the commonest in Africa. 1, 2 The incidence of melanoma has been increasing exponentially especially, in Australia and Asia, occurring predominantly on the sun exposed face 
and trunk. However, in Africa it is commonly seen on the sole of the foot. ${ }^{2}$, 4,6

While the exact cause of skin cancers is not known, certain risk factors have been identified. Ultraviolet irradiation from sunlight is playing an increasingly important role as the ozone layer gets depleted. The exponential increase of skin cancers in the western world, particularly malignant melanoma in Australia is associated with this. 1,68 Chronic infective ulcers and burns scars predispose to squamous cell carcinoma (Marjolin's ulcers). This is thought to be common in Africa. 1,2 The ulcer is usually of short duration which, $10-15$ years in contrast to $30-40$ yearś seen in developed countries. $3,7,8$

Dermal tumours also appear to be universally common and Kaposi's sarcoma is the commonest of these in Africa. 2 The human immunodeficiency virus/ acquired immune deficiency syndrome (HIV/AIDS) pandemic has significantly increased the frequency of this tumour. This is a histopathologic review of malignant skin tumours in Jos, Nigeria.

\section{Materials and Methods}

This is a retrospective study of histologically confirmed skin cancers seen at the Jos University Teaching Hospital, Jos, Nigeria in the period 1994 - 1998 inclusive. The biopsies were mainly excision biopsies sent to the histopathology laboratory in $10 \%$ formal saline solution. Information was collected from case notes and referral forms, and this included clinical data regarding age, site of lesion, nature of lesion, duration of symptoms and method of therapy. Confirmed secondaries and inadequate samples were excluded frc $n$ the study. The tissue were processed and embedded in paraffin wax and stained with standard haematoxyline and eosin stains. The tumours were categorised by anatomical location and histologically classified."

\section{Results}

There were a total number of 2071 malignancies seen at the histopathology laboratory during the period, of which

\section{Table 1: Histological Types of Skin Cancer}

Type of skin cancer

Epithelial Tumours

Squamous cell carcinoma

Malignant melanoma

Basal cell carcinoma

Dermal Tumours

Kaposi's sarcoma

Fibrosarcoma

Malignant fibrous histiocytoma

Adnexal tumours
No. $(\%)$

$65(51.1)$

$31(24.7)$

5 (3.9)

$14(10.9)$

$6(4.7)$

$5(3.9)$

$3(2.3)$ 


\begin{tabular}{lrrrrrrr}
\hline \multirow{2}{*}{ Skin cancer } & \multicolumn{5}{c}{ Site } & Total (\%) \\
\cline { 2 - 7 } & Leg & Foot & Back & Scalp & Face & \\
\hline Squamous cell carcinoma & 21 & 15 & 9 & 11 & 9 & $65(51.1)$ \\
Malignant melanoma & 6 & 23 & 2 & - & - & $31(24.1)$ \\
Kaposi's sarcoma & 3 & 7 & - & - & 2 & $12(9.4)$ \\
Fibrosarcoma & 1 & 3 & 1 & 2 & - & $6(4.7)$ \\
Basal cell carcinoma & - & - & 2 & 3 & - & $5(3.9)$ \\
Malignant fibrous & - & 2 & 2 & 1 & - & $5(3.9)$ \\
Histiocytoama & - & - & - & 2 & 1 & $3(2.3)$ \\
Adnexal tumours & & & & & & & $128(100)$ \\
Total & & &
\end{tabular}

Table 3: Age of 112 Patients with Skin Cancer

Type of cancer

Age (Years)

Total

$20 \quad 21-30 \quad 31-40 \quad 41-50 \quad 51-60 \quad 61+$

\begin{tabular}{lrrrrrrr}
\hline Squamous cell carcinoma & 6 & 1 & 10 & 11 & 14 & 9 & 51 \\
Malignant melanoma & - & 1 & 4 & 5 & 9 & 10 & 29 \\
Kaposi's sarcoma & - & 3 & 3 & 5 & - & - & 11 \\
$\begin{array}{l}\text { Adnexal tumours } \\
\text { Fibrosarcoma }\end{array}$ & 2 & - & - & - & 2 & 3 & 7 \\
$\begin{array}{l}\text { Malignant fibrous } \\
\text { histiocytoma }\end{array}$ & - & 3 & - & 1 & 2 & - & 6 \\
Basal cell carcinoma & 1 & - & - & - & 1 & 3 & 5 \\
Total & 9 & 8 & 19 & 23 & 28 & 25 & 112 \\
\hline
\end{tabular}

- In 16 patients the age was not specified.

$128(6.18 \%)$ were primary malignancies of the skin. Sixty-five $(51.5 \%)$ of the skin cancers were squamous cell carcinoma, malignant melanoma $31 \quad(24.7 \%)$, Kaposi's sarcoma $14(10.9 \%)$ and others less frequent cancers (Table 1).

The lesions presented as non-healing ulcers or exophytic, nodular growth which where solitary or multiple. Majority of the tumours $(47.2 \%)$ were situated on the leg or foot (Table 2). The epithelial tumours and Kaposi's sarcoma occurred predominantly on the lower limbs. Five of the 14 patients with Kaposi's sarcoma were HIV positive. The incidence of epithelial tumours appeared to increase with age (Table 3 ).

\section{Discussion}

Squamous cell carcinoma was the commonest skin cancer in this report as in previous reports from Lagos and Jos, 


\section{Malignant Skin Tumours in Jos. B. M. Mandong et al}

Nigeria and Kenya.1, 2 The predominance of squamous cell carcinoma and malignant melanoma is similar to other reports from Africa. 1, 2, 10 The Caucasian populations of Europe and America however shows a preponderance of basal cell carcinoma. $3,4,10$ Malignant melanoma is thought to be increasing exponentially particularly in the Australia. This has been attributed to depletion of the ozone layer. ${ }^{4}$

Squamous cell carcinoma was found commonly on the lower limbs, scalp and face. Majority (60\%) of them were Marjolin's ulcer arising from chronic ulcers and scars, usually of $5-10$ years standing. The reasons are not known, however, poor nutrition, decreased local blood circulation and rapid regenerative capacity of squamous epithelium have been implicated. This is in contrast to reports from Europe and America, 8, 10 where many of the ulcers are of $30-40$ years standing. It appears squamous cell carcinoma tended to occur in exposed parts of the body. Malignant melanoma in the Caucasian follows such a pattern; however it almost uniformly occurred on the foot in our patients. The explanation for this is not clear, but chronic irritations from walking barefooted and absorption of ultraviolet rays from sand have been suggested. $0-8,10$ It was however noted that squamous cell carcinoma was not found in the anal region as reported in some parts of Africa. ${ }^{2}$

Kaposis sarcoma was the commonest dermal tumour, accounting for $10.94 \%$ of the skin cancer cases. Majority of the patients presented with the classical African Kaposi, associated with HIV seropositivity in $36 \%$. This sarcoma is largely associated with diminished immune surveillance. Recently, however, a Kaposi's sarcoma associated adenovirus has been described in both the sporadic and endemic types. 7
In conclusion, this study provides a database, which will be useful in future, studies on skin cancers in our environment, and for the surveillance.

\section{Acknowledgment}

We acknowledge the contributions of Mr. James Goyit of Cancer Registry, Jos University Teaching Hospital for providing some of the data and $\mathrm{Mr}$ Monday Akwu Uchola for the secretarial assistance.

\section{References}

1. Adeyi $O$, Banjo AA. Malignant tumours of the skin. A six-year review of histologically diagnosed cases (1990 - 1995). Nigerian Quarterly Journal of Hospital Medicine 1998; 2: 99-102.

2. Edington GM, Gilles HM. Malignant disease in the tropics. In: Pathology in the tropics. Arnold, $1976 \mathrm{pp}$ $702-709$.

3. Steven GB, Katherine K, David GB, Karn AH. The many faces of squamous cell carcinoma. Dermatol Surg 1996; 22: 243 - 254.

4. Murphy GF, Mihm MC. The skin In: Cortran RS, Kumar V, Robbins SL (eds). Robbins pathological basis of disease. Saunder, Philadelphia, 1999 pp 1174 - 1189.

5. Roberts AS. Skin cancer. In: Roberts AS (ed). Skin cancer recognition and management. Springer-Verlag, London, pp 1- 10.

6. Igun GO. Critical decision in surgical management of malignant melanoma of the foot. Niger Postgrad Med J 1998; 5: 86 - 88.

7. Tania JP, Salah MS, Jag B, Gary SR. Burn scar carcinoma. Dermatol Surg 1998; 24: 561 - 565. 
8. Margaret TD, John DB, Mark WL. Marjolin's ulcer arising in a burn scar. Cancer 1998; 62: 49-51.

9. Histological typing of skin tumours. In: International histological classification of tumours. World
Health Organisation, Geneva, 1974 , No. 12.

10. Lever WF, Lever GS. Tumours of vascular tissue. In: Histopathology of the skin. Lippincott, Philadelphia, 1983 pp $636-640$. 